\title{
Editorial
}

\section{Building Mathematical Models for Multicriteria and Multiobjective Applications}

\author{
Adiel T. de Almeida, ${ }^{1}$ Love Ekenberg, ${ }^{2,3}$ Martin J. Geiger, ${ }^{4}$ \\ Juan Carlos Leyva Lopez, ${ }^{5}$ and Danielle Morais ${ }^{1}$ \\ ${ }^{1}$ Department of Management Engineering, Federal University of Pernambuco, 50670-901 Recife, PE, Brazil \\ ${ }^{2}$ International Institute for Applied Systems Analysis (IIASA), Schlossplatz 1, 2361 Laxenburg, Austria \\ ${ }^{3}$ Department of Computer and Systems Sciences, Stockholm University, 16407 Stockholm, Sweden \\ ${ }^{4}$ Logistics Management Department, University of the Federal Armed Forces, Holstenhofweg 85, 22043 Hamburg, Germany \\ ${ }^{5}$ Department of Economic and Management Sciences, University of Occident, 80040 Culiacán, SIN, Mexico
}

Correspondence should be addressed to Adiel T. de Almeida; adiel.almeida@pq.cnpq.br

Received 17 July 2016; Accepted 17 July 2016

Copyright (C) 2016 Adiel T. de Almeida et al. This is an open access article distributed under the Creative Commons Attribution License, which permits unrestricted use, distribution, and reproduction in any medium, provided the original work is properly cited.

In our daily lives or professional settings, there are many decision problems involving multiple criteria, which may be conflicting and incommensurable. The complexity of realworld decision and the plethora of factors involved necessitate the implementation of sound theoretical frameworks for structuring decision-making processes. Multicriteria Decision Making/Aid (MCDM/A) and multiobjective methods can be highly useful for decision makers (DMs) in such tasks.

Multicriteria and multiobjective approaches provide a wide variety of methodological tools for supporting the DMs when facing real-world decision problems when designing and analyzing mathematical models, representing both the preferences of decision makers and the various characteristics of the decision problems at hand in a number of areas.

There is nevertheless still a need for further developments of multicriteria and multiobjective models and applications in order to meet an increasing demand for solving complex problems. The aim of this special issue is therefore to further expand the field and to promote and disseminate research and applications among academics and other professionals interested in theories, methodologies, and applications of multicriteria and multiobjective approaches for tackling complex problems in a wide variety of areas.

The special issue received a high number of high-quality submissions. After a rigorous peer-review process, with an acceptance rate of about $18 \%$, ten accepted papers provide a variety of applications for real-world problems while combining theoretical methodology and mathematical analysis. The authors of these papers are from Brazil, China, Spain, Taiwan, and Turkey.

This selection of papers reflects the diversity of research studies applying different multicriteria and multiobjectives methods and includes theoretical procedures being developed for different areas as well as practical experiments for validating these.

In the area of information system, A. P. H. de Gusmão and C. P. Medeiros present a study with an additive model used to evaluate alternatives for selecting a strategic information system using FITradeoff, which is a new method for eliciting the weights of criteria. The FITradeoff has the advantage of requiring less effort from the decision-maker when expressing preferences regarding weights of criteria, minimizing the risk of inconsistent answers. The model is using data from a glass packaging factory to select a single information system from a set of systems previously identified as relevant.

Dealing with evaluation of the security level of a city, C. J. J. de Figueiredo and C. M. M. Mota show mapping locations for the occurrence of robberies applying the multicriteria method Dominance-Based Rough Set Approach. With this 
classification model, it is possible to understand the social dynamics and also to propose strategies against violence.

R.-C. Chen and S.-P. Suen propose a multiobjective mechanism to help retail industry practitioners to optimize the allocation of stores. The model is based on three phases. Firstly, all stores are divided into clusters using a geographic information system (GIS) and $k$-means clustering algorithm. Secondly, stores are strategically selected according to the requirements of the company and the attributes of the stores. And finally, it is determined which stores to close by using a neighborhood-based multiobjective genetic algorithm (NBMOGA).

Considering Earned Value Management (EVM) system, which is applied to monitor and control organizations' projects to attain high performance, S.-Y. Chou et al. employ a hybrid multiple criteria decision-making (HMCDM) procedure for achieving aspired EVM projects' performance. The proposed procedure quantifies gap indices with respect to aspiration levels of EVM based on interinfluence effects among criteria/dimensions/alternatives and systemizes the quantitative results in the context of influential network relation maps (INRM), helping managers to find routes for EVM application decisions. This study demonstrates the importance of adopting a systematic procedure to analyze interinfluenced criteria associated with the EVM application decisions.

In view of service related to environmental sector, L. Delgado-Antequera et al. design a framework to solve waste collection problems applying an Asymmetric Vehicle Routing Problem (AVRP) with side constraints and several variations. This model is based on an interactive biobjective method for minimizing the total distance travelled by all vehicles and the length of the longest route to balance the working day within the fleet of vehicles. The model helps the companies in charge of waste management in obtaining a better planning of their services.

Regarding the aerospatial field of research, L. Jia et al. propose an integrated decision model based on combination weighting and multiattribute intelligent grey target to calculate aircraft combat survivability, that is, the capability of an aircraft to avoid or withstand a man-made hostile environment.

Another paper in this research field is presented by A. Mateos and A. Jiménez-Martín, who investigate air traffic control systems while applying the multiobjective optimization simulated annealing algorithm for collision avoidance in ATM, accounting for three admissible maneuvers (velocity, turn, and altitude changes). The emphasis is on the minimization of the maneuver number and magnitude, time delays, or deviations in the leaving points. This study is especially important to improve the safety standards in free flight unstructured environments.

For the industrial sector, T. Kellegöz presents a goal programming model as well as heuristic methods based on a variable neighborhood search approach for multiobjective assembly line balancing problems with multimanned stations. This model minimizes the total number of multimanned stations as well as the total number of workers for smoothing the number of personnel at the stations.
Another strategic application concerns power projection, that is, a military term referred to the capacity of a state to apply national transportation networks for crisis response, which is a crucial element of a state's military power in modern warfare. Focused on this research field, H.-L. Bi et al. present a hub location problem in the design of power a projection network from a resilience perspective. The authors propose a biobjective and trilevel integer programming model for analyzing tradeoffs between the performances of the projection network in different situations. Besides considering the cost of the projection network in normal situations, it also analyzes the performance in presence of hub disruptions.

In the civil construction sector, P. Palha et al. deal with subcontractors' selection problems considering various attributes, such as variations in projects and type of activity. The authors present an additive sorting method for categorizing activities to be outsourced in civil construction based on the ROR-UTADIS method, including new forms of supplying preference information.

Despite the significant spread of method and applications presented herein, this special issue can only cover a small diversity of areas of the recent developments and applications in the fields. Our intention is merely to demonstrate the broad usability of multicriteria and multiobjective methods of high standards and it is our hope that it will inspire and stimulate further development of mathematical models for multicriteria and multiobjective applications in the future.

\section{Acknowledgments}

We would like to express our deepest gratitude to the authors for their contributions to this special issue and the cooperation and assistance of many reviewers, whose feedback was very useful in improving the quality of papers submitted.

Adiel T. de Almeida Love Ekenberg Martin J. Geiger Juan Carlos Leyva Lopez Danielle Morais 


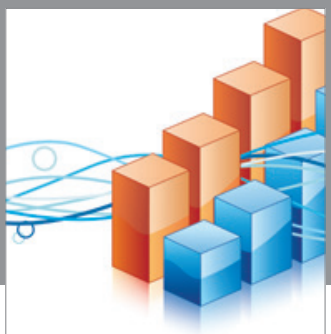

Advances in

Operations Research

vatem alat4

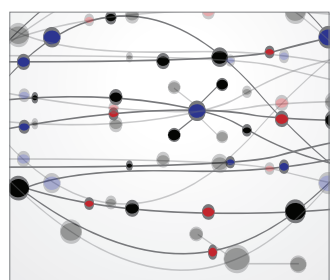

\section{The Scientific} World Journal
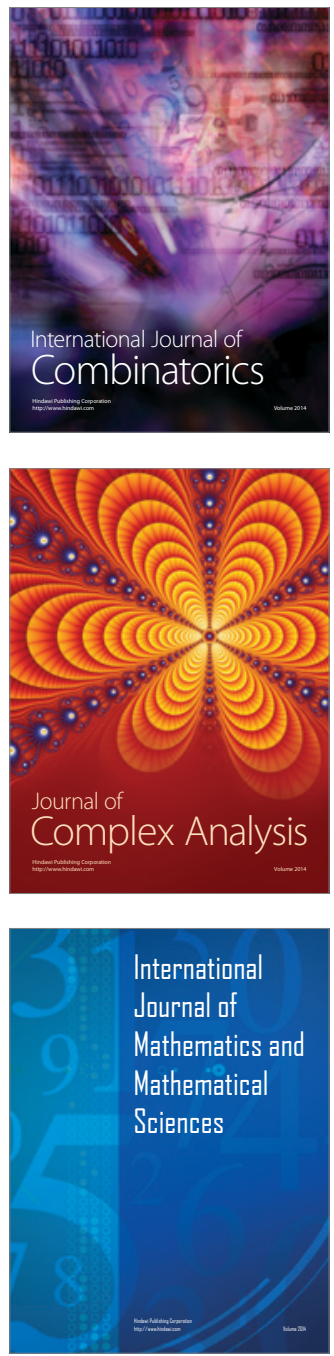
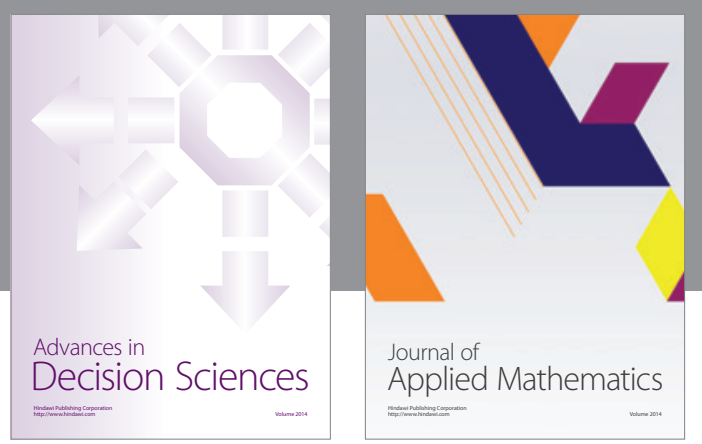

Algebra

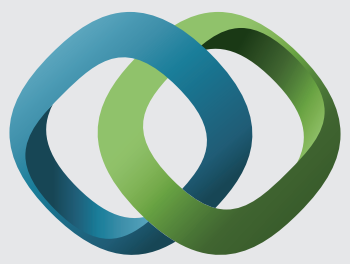

\section{Hindawi}

Submit your manuscripts at

http://www.hindawi.com
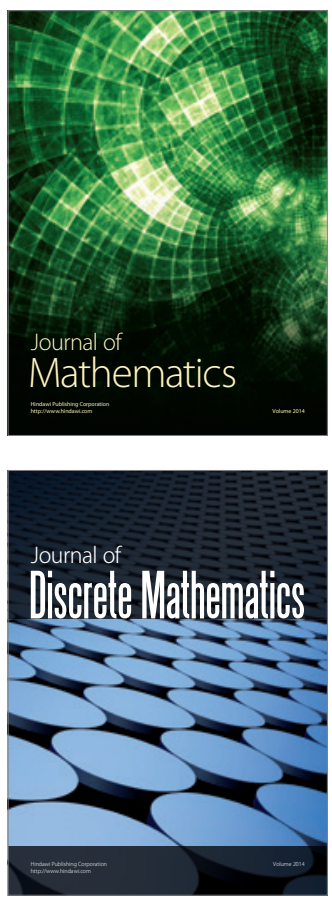

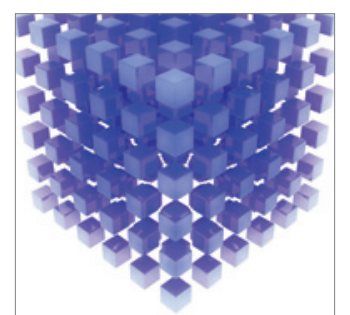

Mathematical Problems in Engineering
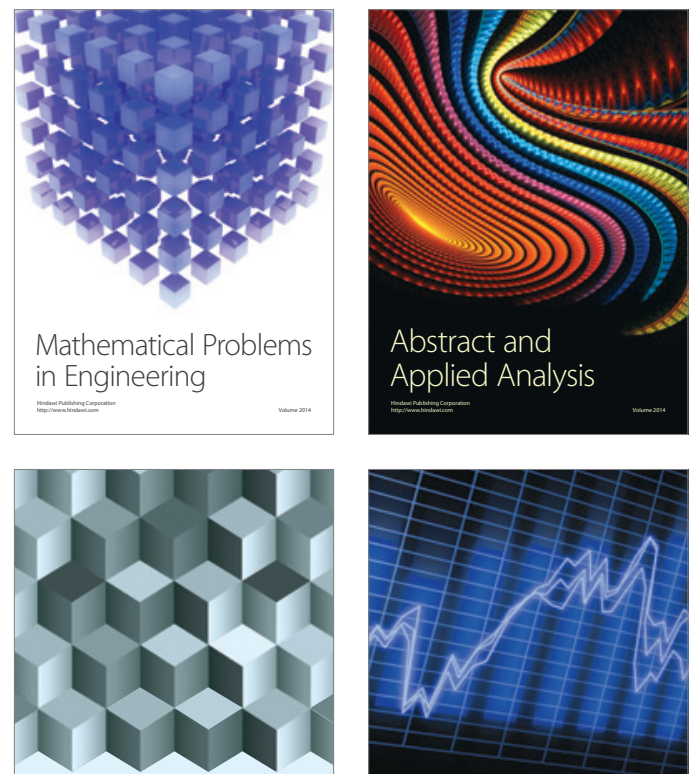

Journal of

Function Spaces

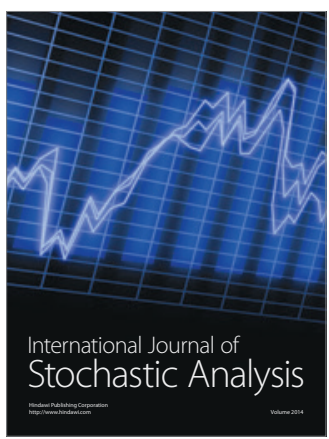

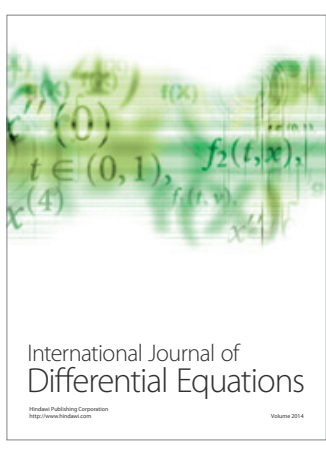
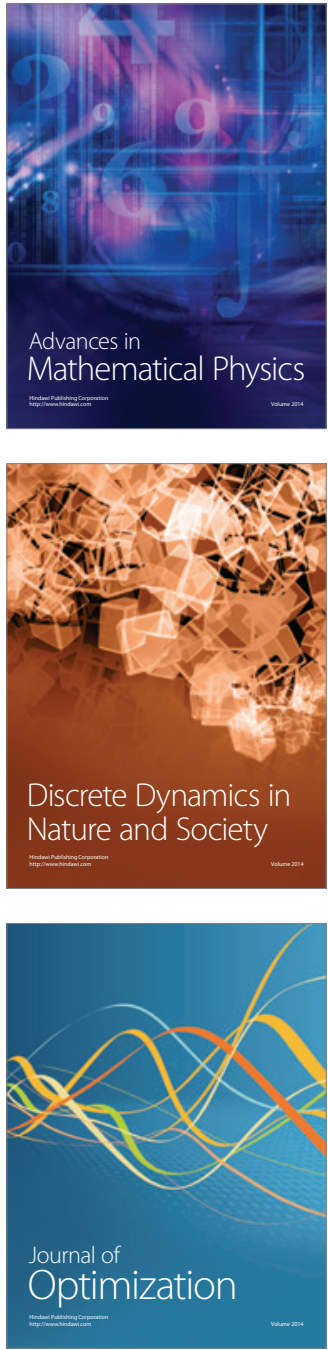